\title{
Ciência e Hermenêutica \\ da Facticidade: Heidegger e o \\ Projeto de uma Filosofia Científica
}

Prof.Dr. Alexandre Franco de Sá À memória de Franco Volpi

O artigo discute a pretensão da ontologia fundamental de Martin Heidegger como 'filosofia científica', na segunda década do século XX. Segundo Heidegger, o projeto de uma ontologia fundamental, baseado no método fenomenológico e em uma hermenêutica da facticidade, deveria ser perguntar pelo modo de ser do ente capaz de colocar a questão ontológica sobre o ser, o Dasein. Heidegger posteriormente discute sobre a incapacidade de levar tal projeto a cabo. O presente artigo pretende tratar das razões desse fracasso, e dividir-se-á em três momentos. Num primeiro momento, procuramos caracterizar o termo 'científico' no que ele significa em uma 'filosofia científica'. Em um segundo momento, procuramos explicar como o projeto heideggeriano de uma ontologia fundamental pode ser considerado como a execução de uma filosofia científica. No último momento, se tentará esclarecer como o projeto de Heidegger de uma filosofia científica é capaz de explicar o próprio fracasso da ontologia fundamental.

PALAVRAS-CHAVE

Filosofia científica; hermenêutica da facticidade; ontologia fundamental; fenomenologia; outro início.

The article discusses the claim of fundamental ontology of Martin Heidegger as 'scientific philosophy', in the second decade of the XX century. According to Heidegger, the project of a fundamental ontology, based on the phenomenological method and the hermeneutics of facticity, should be asked by way of being of being able to put the ontological question of being, the Dasein. Posteriorly Heidegger discusses the inability to carry out such a project. This article wants to address the reasons for this failure, and will be split in three parts. At first, we characterize the term 'scientific' what he means in a 'scientific philosophy'. In a second step, we explain how the project a Heideggerian fundamental ontology can be considered as the execution of a scientific philosophy. At the last moment to try to clarify how the project of a scientific philosophy of Heidegger is able to explain the failure of fundamental ontology.

KEY-WORDS

Scientific philosophy; hermeneutics of facticity;

fundamental ontology; phenomenology; other beginning. 
A conjugação entre os dois conceitos que constituem o título desta comunicação - ciência e hermenêutica da facticidade - evoca imediatamente o projeto que dirigiu o pensamento de Martin Heidegger ao longo dos anos 20 do século passado, o qual, como se sabe, pode ser caracterizado como o projeto da constituição de uma ontologia fundamental. Esta ontologia, segundo Heidegger, seria uma filosofia caracterizável como "científica", a qual, baseada no rigor do método fenomenológico, deveria partir do acesso hermenêutico ao modo de ser fáctico do ente capaz de perguntar pelo ser e de fundar, nessa medida, a própria ontologia.

Um tal projeto não foi consumado no âmbito do pensamento heideggeriano. E o que caracteriza, em larga medida, a filosofia de Heidegger, na especificidade do seu percurso, é precisamente o fato de ela ser um desenvolvimento a partir da consciência dessa não consumação. Interessa-nos aqui, por isso, sobretudo abordar as razões desta não consumação. Heidegger dirá mais tarde, refletindo sobre a não continuidade do projeto traçado nos anos 20 , que se tinha tratado de uma incapacidade para encontrar na linguagem da metafísica a expressão suficiente daquilo que estava já então a ser pensado. ${ }^{1}$ No entanto, diante de tal explicação, importa insistir na pergunta, perguntando pela razão de fundo de faltar a Heidegger uma linguagem suficiente para que o projeto pudesse ser levado a cabo. Que se encontrava afinal na estrutura do projeto para que este tivesse ficado preso na "linguagem da metafísica"? Como se pode explicar que o próprio projeto de uma ontologia fundamental inviabilizasse, em determinado momento da sua elaboração, o propósito da sua constituição como o corpo doutrinal de uma filosofia tornada científica?

Para ensaiar uma resposta a estas questões, importa aqui percorrer três tópicos que constituirão, nessa medida, os marcos essenciais da presente exposição. Em primeiro lugar, se o projeto de Heidegger foi caracterizado pela sua intenção de constituir uma filosofia científica, temos de considerar, antes de mais nada, aquilo a que nos referimos através deste conceito. Em segundo lugar, circunscrito o conceito de uma "filosofia científica", importa considerar em que medida o projeto heideggeriano de elaboração de uma ontologia fundamental, a qual se deveria desenvolver com base numa hermenêutica da facticidade, participa deste propósito da constituição da filosofia como ciência. Finalmente, em terceiro lugar, tematizar-se-á em que medida a caracterização do projeto heideggeriano - o projeto de elaboração de uma hermenêutica da facticidade como projeto de constituição de uma "filosofia científica" - pode contribuir para compreender o estado de incompletude e de não consumação em que o pensamento heideggeriano o deixou.

1 Cf. Martin Heidegger, "Brief über den »Humanismus«", in Wegmarken, Frankfurt a. M., Vittorio Klostermann, 1976, Gesamtausgabe, vol. 9 [edição citada doravante como "GA“, seguida do número do volume], p. 328. 
Começando pelo primeiro tópico mencionado, poder-se-ia dizer, antes de mais, que, se perguntarmos pelo fator que mais radicalmente caracteriza a filosofia moderna, este não pode deixar de aparecer como o projeto da conquista para o saber de um fundamentum inconcussum, um fundamento absolutamente certo, seguro e incontestável. É a partir deste projeto que a modernidade se começa a compreender a si mesma como correspondendo ao advento de uma nova era filosófica, a partir da qual a filosofia se deveria constituir como aquilo a que se poderia chamar uma "filosofia científica". E o aparecimento da era da constituição da filosofia como ciência seria marcada por duas mudanças fundamentais no âmbito do pensamento filosófico. Por um lado, sendo a filosofia determinada agora pelo seu desenvolvimento a partir de um fundamento absolutamente certo e seguro, dir-se-ia que esta mesma filosofia se constituiria como científica na medida em que deveria ser possível, com base num tal fundamento suficiente, o progresso e a acumulação do saber ao longo da sucessão de gerações. A filosofia científica corresponderia então, antes de mais, à inauguração da era da construção, lenta e progressiva, da própria filosofia como ciência. Por outro lado, se a filosofia científica deveria ser caracterizada pela acumulação progressiva do saber com base num fundamento já inamovível, tal quereria dizer que a manifestação mais própria do seu aparecimento deveria consistir no abandono pela filosofia da concepção da sua história como a sucessão temporal de um conjunto anárquico de doutrinas contrapostas, dogmaticamente estabelecidas e insuficientemente fundadas, e na consequente abertura da possibilidade de conceber a história da filosofia como uma história filosófica da razão, marcada pela própria constituição da razão ao longo do imprescindível desenrolar-se desta mesma história.

Estes dois aspectos que deveriam assinalar o aparecimento de uma filosofia científica são inseparáveis, mas não coincidentes. E é a sua conjugação que permite diferenciar, na sua especificidade, os projetos concretos da constituição da filosofia como ciência.

Assim, se pensarmos no legado da filosofia transcendental kantiana, torna-se claro que, para o projeto crítico, se tratava, antes de mais, de abrir para a filosofia uma nova era, assente no progresso proporcionado pela capacidade de um saber filosófico se interrogar previamente, nas construções teóricas que leva a cabo, sobre os seus limites e as suas condições de possibilidade. $\mathrm{O}$ projeto crítico kantiano se concentra assim naquilo a que se poderia chamar o momento fundacional da constituição da filosofia como ciência. Ele centra-se na sua in- 
tenção de proporcionar uma "nova era filosófica" - uma era da crítica - na qual a filosofia se caracterizasse por um fundamento suficiente para o seu progresso e desenvolvimento.

À concentração do projeto crítico neste momento fundacional corresponde, por seu lado, um desinvestimento na dimensão histórica que a intenção de constituir a filosofia como ciência não poderia deixar de trazer consigo. Se os dois aspectos mencionados não são separáveis, é certo que também já em Kant não pode deixar de surgir a inevitabilidade de uma nova filosofia científica se confrontar com a história da filosofia. É como manifestação desta inevitabilidade que aparece no pensamento crítico de Kant a menção a um peculiar "destino" da razão: o "destino" que se traduz na tendência para se "concluir o seu edifício tão cedo quanto possível e só depois examinar se ele possui bons fundamentos»². É no contexto desta alusão que adquirem sentido as observações de Kant em torno do paralogismo que estaria na base da afirmação cartesiana do "eu penso" como substância pensante ${ }^{3}$. Ou é neste mesmo contexto que Kant pode abordar a anfibolia dos conceitos, pela qual se tornaria claro que o conceito de mónada em Leibniz não traduziria senão a confusão pré-crítica entre o númeno enquanto "coisa em si”, ou seja, enquanto substância considerada aquém do enquadramento espaço-temporal que constitui a condição de possibilidade da receptividade de qualquer objeto, e o fenômeno como objeto próprio do ente que nós mesmos somos enquanto consciências receptivas e sensíveis ${ }^{4}$. A partir destas observações, poder-se-ia dizer que o projeto crítico de Kant conduz já para uma confrontação com a história da filosofia pré-crítica, no seguimento da qual seria possível dizer que a nova era de uma filosofia científica não poderia deixar de ser precedida por uma atitude dogmática que a despoletaria. Contudo, se é verdade que tais passos da Crítica da Razão Pura se encaminham já para uma propedêutica ao aparecimento de uma história filosófica da filosofia, na medida em que neles se procura mostrar como os dogmatismos pré-críticos não podem deixar de ter a sua origem num "destino" intrínseco à própria razão enquanto tal, também é verdade que a crítica kantiana se concentra essencialmente na fundação ou no começo da nova era da filosofia científica, remetendo para um plano secundário a preocupação com o problema de saber como a estrutura da razão lhe despoletou um "destino" marcado pela primordial inevitabilidade do dogmatismo.

2 Immanuel Kant, Crítica da Razão Pura, B9.

3 Idem, B410-411.

4 Idem, A260, B316 ss 
É em contraste com a proeminência daquilo a que se poderia chamar a dimensão fundacional na constituição de uma filosofia científica, tal como aparece na filosofia crítica de Kant, que, por outro lado, pode ser compreendida a concentração de Hegel na elaboração da nova filosofia científica como um sistema a partir do qual fosse possível compreender a filosofia anteriormente elaborada não como um simples dogmatismo acidental, mas como os momentos imprescindíveis de um processo cujo desenvolvimento se identifica com a própria verdade, a qual deveria ser captada na sua integridade justamente por uma filosofia tornada ciência. Para Hegel, tal como para o Kant do projeto crítico, também a filosofia teria chegado ao estágio da sua constituição como ciência. Como ele afirma explicitamente numa conhecida passagem do prefácio à Fenomenologia do Espírito: "A verdadeira figura na qual a verdade existe só pode ser o sistema científico da mesma. Colaborar para que a filosofia se aproxime mais da forma da ciência - do objectivo de poder pôr de lado o seu nome de amor ao saber para ser saber efectivo -, é isto o que me propus". 5 Contudo, a constituição da filosofia como ciência corresponderia não propriamente à conquista de um fundamento a partir do qual o saber filosófico poderia progredir e remeter toda a filosofia anterior para o estatuto de um dogmatismo, arbitrário e infundado, mas antes à constituição de um sistema pelo qual fosse adquirida a consciência de que toda a filosofia passada, longe de ser negligenciável, faria parte de um processo necessário quer para a efetivação da verdade quer para a efetivação da filosofia científica passível de se compreender. Por outras palavras: se, para Kant, a efetivação de uma filosofia científica corresponderia à ultrapassagem de uma especulação dogmática e à sua substituição por uma filosofia crítica, caracterizada pela interrogação prévia dos seus fundamentos, limites e condições de possibilidade, para Hegel, o advento de uma filosofia científica traduzir-se-ia antes na constituição de um sistema capaz de compreender naquilo a que chama a "diversidade dos sistemas filosóficos" não a simples contradição entre eles, mas os momentos necessários daquilo a que se refere como o "desenvolvimento progressivo da verdade". ${ }^{6}$

Com o que fica dito, temos então dois modos de representar o advento de uma "filosofia científica". Uma primeira perspectiva sobre esse advento, herdando o legado kantiano, poderia ser caracterizada, de um modo geral, como fenomenológica, na medida em que se basearia na ideia do começo de uma era filosófica nova a partir de uma delimitação primordial das suas condições

5 G. W. F. Hegel, Phänomenologie des Geistes, (cita-se a trad. de Manuel Carmo Ferreira, in Hegel: Prefácios (Lisboa, INCM, 1990, p. 39).

6 Idem, p. 38. 
de possibilidade. Tal delimitação conduziria à remissão de toda a filosofia anterior para o estatuto de algo ainda insuficientemente fundado. É com base na antevisão desta "nova era filosófica" que Edmund Husserl pode falar, no seu posfácio às Ideias para uma Fenomenologia Pura, de «pôr em obra o início radical de uma filosofia que, para repetir as palavras kantianas, "poderá surgir como ciência"»». ${ }^{7}$ Por outro lado, uma segunda perspectiva sobre o advento de uma "filosofia científica", cujo exemplo paradigmático podemos encontrar na dialéctica de Hegel, assentaria na ideia de que tal advento corresponderia não propriamente a um "início radical" da filosofia, mas apenas a um "outro início" do pensar, ou seja, à aquisição da consciência de que a verdade se encontraria no acontecer de uma história cujo desdobramento coincidiria com a própria verdade. Uma tal perspectiva seria então caracterizada pela exclusão da possibilidade de cindir a história da filosofia entre duas partes contrapostas: entre uma especulação meramente dóxica, que constituiria o "até agora" da filosofia, e uma era genuinamente filosófica que se seguiria do seu começo autêntico. É a partir desta exclusão que Hegel, por exemplo, pode estabelecer a coincidência entre a verdade da filosofia e o seu devir histórico, escrevendo claramente que «o verdadeiro é o devir de si mesmo» cuja efetividade coincide com «o seu desenvolvimento e o seu fim». ${ }^{8}$ E é este legado que estará presente na emergência da história do ser heideggeriana.

Tendo em conta o que foi dito, poderemos agora considerar o segundo tópico que nos propusemos tratar, ou seja, a relação entre o projeto heideggeriano de constituição de uma ontologia fundamental de base fenomenológica e a representação do advento de uma "filosofia científica". Tendo em conta este enquadramento, poderíamos dizer, antes de mais, que o projeto heideggeriano começa por se caracterizar através daquilo a que chamamos uma perspectiva fenomenológica sobre o advento de uma "filosofia científica". Tal como para Husserl, também para o Heidegger dos anos 20 tratar-se-ia de fundar o início de uma filosofia científica a partir da fundamentação proporcionada pela adoção do método fenomenológico. «A fenomenologia» - escreve Heidegger nas

7 Edmund Husserl, „Nachwort: Ideen zu einer reinen Phänomenologie und phänomenologischen Philosophie“, in Husserliana, The Hague, Martinus Nijhoff, 1992, vol. 5, p. 159.

8 G. W. F. Hegel, op. cit., p. 45. 
lições do Semestre de Verão de 1927, em Marburgo - «é o título para o método da ontologia, isto é, da filosofia científica». ${ }^{9}$ E a adoção de um tal método proporcionaria a possibilidade de viabilizar o início radical - um início inteiramente novo - daquilo a que Heidegger chama, nas suas últimas lições proferidas em Marburgo, um ano mais tarde, uma "metafísica autêntica". Como escreve Heidegger nessas lições, ao rememorar o último diálogo que tivera com Max Scheler, em Dezembro de 1927: «O problema da relação sujeito-objeto deve ser colocado de um modo completamente novo e livre dos ensaios que até agora surgiram. [...] E aquilo que é mais essencial: está aí o instante, precisamente na desolação da situação filosófica que é pública, de voltar a ousar a passagem para a metafísica autêntica [eigentliche Metaphysik], isto é, de a desenvolver a partir do solo». ${ }^{10}$

Um tal início deveria ser preparado, como se sabe, através da análise daquilo a que Heidegger chama "Dasein", ou seja, do ente cuja constituição ôntica consistiria precisamente em compreender e perguntar pelo ser dos entes. É uma tal análise preparatória que, de acordo com o plano traçado no $\S 8$ de $\operatorname{Ser} e$ Tempo, em 1927, deveria constituir a primeira parte do projeto de elaboração de uma ontologia fundamental. E esta primeira parte dever-se-ia desenvolver a partir da transição da análise preparatória do Dasein para uma tematização do ser em geral, e desta para metontologias ou ônticas metafísicas completas, as quais constituiriam assim aquilo a que se poderia chamar o "corpo doutrinal" de uma filosofia científica fundada fenomenologicamente. É para a designação desta transição que pela primeira vez aparece no âmbito do pensamento heideggeriano o termo "viragem" (Kehre). Se a análise preparatória do Dasein conduziria à determinação do ser deste ente como temporalidade (Zeitlichkeit), a construção fenomenológica proposta por Heidegger poder-se-ia caracterizar como um movimento de viragem da analítica preparatória da temporalidade do Dasein para uma análise completa da temporalidade específica do próprio ser, ou seja, da sua temporaneidade ou temporalitas (Temporalität), a partir da qual o corpo teórico metontológico - o corpo teórico de ônticas metafísicas ou ontologias regionais - poderia ser constituído e cientificamente fundado. Como escreve explicitamente Heidegger, nas suas lições de 1928: «Este todo da fundamentação e elaboração da ontologia é a ontologia fundamental; ela é 1) analítica do Dasein e 2) analítica da temporaneidade do ser. No entanto, esta analítica temporânea é, ao mesmo tempo, a viragem na qual a própria ontologia explicitamente recua para a ôntica metafísica na qual explicitamente sempre se mantém. Trata-se de, através da mobilidade da radicalização e da universaliza-

9 Martin Heidegger, Grundprobleme der Phänomenologie, GA24, p. 27.

10 Martin Heidegger, Metaphysische Anfangsgründe der Logik im Ausgang von Leibniz, GA26, p. 165. 
ção, trazer a ontologia à transição que nela está latente. Realiza-se aí o virar e chega-se à transição para a metontologia». ${ }^{11}$

Contudo, se é verdade que o projeto heideggeriano começa por basear-se na ideia da fundação de uma nova era filosófica, assente numa construção fenomenológica que conduzisse, através de uma análise preparatória do Dasein, a uma filosofia científica completa, um tal projeto é especificado por a sua efetivação não poder deixar de dar lugar, segundo Heidegger, a uma confrontação com os marcos fundamentais do pensamento filosófico - Kant, Descartes e Aristóteles - que constituem, nesta medida, a tradição ontológica. Uma tal confrontação deveria ter lugar, segundo o plano estabelecido no $§ 8$ de Ser e Tempo, em toda a segunda parte da obra, preparada pela terceira e última seção da sua primeira parte (ou seja, em toda a parte de Ser e Tempo que ficou por publicar). Esta confrontação consistiria, como se sabe, numa "destruição" da tradição ontológica ocidental não no sentido da sua Zerstörung, não no sentido de um puro e simples aniquilamento ou eliminação, mas no sentido de uma sua Destruktion, ou seja, no sentido de uma desobstrução do acesso a esta mesma tradição, naquilo que ela tem de originário e inicial. Assim, se a primeira parte do projeto heideggeriano - a parte respeitante a uma construção fenomenológica - não poderia deixar de ser acompanhada de uma "destruição" (no sentido mencionado da Destruktion), dir-se-ia que o projeto heideggeriano se especifica enquanto projeto fenomenológico por a história da filosofia não ser para ele um mero registo dóxico descartável, mas antes um percurso de pensamento sem cuja referência a própria construção de uma ontologia fundamental de base fenomenológica a qual é sempre uma construção em confrontação com ela - não seria sequer possível. Tal quer dizer então que, se Heidegger começa por apresentar o seu projeto filosófico a partir de uma perspectiva que representa o advento de uma filosofia científica como correspondendo a um "início radical" da filosofia, a própria estrutura deste mesmo projeto, ao assentar no pressuposto de que a construção fenomenológica requer sempre uma destruição concomitante, desloca já as condições iniciais em que ele é apresentado. Numa palavra: com o conceito de destruição, o "início radical" desloca-se já para um "outro início", o qual não pode deixar de consistir numa retomada mais originária - e, nesse sentido, numa retomada destrutiva - do "primeiro início" que na tradição se encerra. Por outras palavras: tal quer dizer que, embora o projeto filosófico heideggeriano se apresente como a fundação de uma nova era filosófica, baseada numa ontologia fundamental fundada numa construção fenomenológica, a estrutura desse mesmo projeto, ao tornar a "destruição fenomenológica" concomitante

11 Idem, p. 201. 
da própria "construção", determina como sua característica fundamental a ideia de que não há eras históricas radicalmente novas e de que todo o início não é, afinal, senão um reinício - um "outro início" relativamente ao "primeiro início" - que, a cada passo, sempre se lhe depara como um desafio.

A questão subjacente ao segundo tópico que nos propusemos abordar - a da caracterização do projeto heideggeriano à luz da ideia de uma filosofia científica - pode então, com o que fica dito, começar a ser respondida. Por um lado, dir-se-ia que o projeto heideggeriano assenta certamente na ideia fenomenológica da constituição de uma filosofia científica. Mas dir-se-ia também que ele recusa fazê-lo atribuindo à tradição filosófica o estatuto de uma especulação simplesmente acrítica e opinativa. Dessa recusa surge em Heidegger o propósito da elaboração de uma "destruição" fenomenológica desta mesma tradição. Por outro lado, apesar de a tradição não constituir para Heidegger um conjunto de opiniões ultrapassadas, tal não significa que ele procure encontrar na história, como Hegel, um processo em cujo desenvolvimento dialético a própria verdade tem a sua gênese. Pelo contrário: a ontologia fundamental, longe de poder ser considerada como um momento no interior de um sistema dialético que a ultrapassa, é, para Heidegger, um autêntico início do pensar filosófico. Como Heidegger dirá explicitamente nas Contribuições para a Filosofia: «O tempo dos "sistemas" passou». ${ }^{12}$ E tal quer dizer que o "outro início" do pensar que é evocado pela ontologia fundamental não é um segundo, mas um início que é "outro" em relação ao início que vigorou na história que teve lugar até agora: um início que se inicia precisamente na alteridade ou, o que aqui é o mesmo, na confrontação (Auseinandersetzung) com essa história. ${ }^{13}$

Assim, o início para o qual Heidegger remete se baseia precisamente na ideia de que a temporalidade do Dasein não é a base para uma história do progresso da razão ou para um sistema do desenvolvimento sistemático da filosofia, mas a estrutura que, estando subjacente à compreensão do Dasein enquanto tal, permite compreender que na história da filosofia, como escreve Heidegger, não sendo dito o "igual", é contudo sempre dito o "mesmo". É por isso que, para Heidegger, o projeto de uma "destruição" da tradição filosófica não faz com que a sua atenção deixe de se concentrar naquilo a que chama a análise preparatória do ente cuja constituição ontológica consiste em compreender. O acontecer do pensar, o compreender dá-se sempre na existência fáctica do $D a$ -

12 Martin Heidegger, Beiträge zur Philosophie (Vom Ereignis), GA65, p. 5.

13 Idem, p. 58: «Ele [o início] é a essenciação do próprio ser. Mas este início só é realizável como o outro em confrontação com o primeiro.» 
sein a partir da sua estrutura. E tal quer dizer que a abordagem do compreender não pode consistir na distinção de épocas históricas, ou de eras diferenciadas na sua compreensão do ser, mas numa hermenêutica da facticidade da existência do ente cuja constituição ontológica, consistindo precisamente neste mesmo compreender, é determinada por uma temporalidade e por uma historicidade estruturais, excludentes, nessa medida, da representação da história como uma sucessão progressiva ou como um desenvolvimento sistemático ao longo de eras diferenciadas. A temporalidade é para o Dasein, como escreve Heidegger nas suas lições do Semestre de Verão de 1923, às quais chama precisamente Ontologia (hermenêutica da facticidade), o seu "hoje". E o "hoje" do Dasein não é um momento evanescente, integrado num tempo cujo "ontem" e o "amanhã” se podem dele diferenciar, mas aquilo a que Heidegger, nestas lições, chama o "como" da sua facticidade ${ }^{14}$, ou seja, o modo concreto e fáctico pelo qual o Dasein é no decurso da temporalidade determinante da sua constituição de ser.

A partir desta "temporalidade", enquanto "fenômeno fundamental da facticidade", poder-se-ia dizer que a expressão "hermenêutica da facticidade" assume no pensamento de Heidegger um duplo significado, determinado pelo sentido simultaneamente objetivo e subjetivo do genitivo que nela se manifesta. A hermenêutica da facticidade significa certamente, antes de mais, o desenvolvimento de um pensamento que tem como objeto da sua análise a facticidade do Dasein. Neste sentido, falar de hermenêutica da facticidade significa, antes de mais, ter a facticidade do Dasein por tema. Contudo, para além deste sentido, se tivermos em conta que a facticidade constitui o "como" do Dasein, determinado pela temporalidade como o seu "fenômeno fundamental", poderíamos dizer que a expressão significa igualmente que a interpretação do Dasein, o modo como este se compreende a si mesmo na sua hermenêutica, pertence sempre à sua própria facticidade e é apropriada pelo seu "como". Noutros termos, tal quer dizer que o Dasein, na hermenêutica que desenvolve em torno da sua própria facticidade, não pode deixar de ser já sempre imediatamente marcado pela apropriação da sua compreensão por essa mesma facticidade e pela estrutura que a determina. Aquilo a que Heidegger chamará, nos anos 30, o Ereignis-denken, o "pensar do acontecimento-apropriante", encontra aqui já a sua emergência. O projeto heideggeriano de uma construção fenomenológica, efetivando-se a partir de uma destruição, torna-se paulatinamente na ideia de uma filosofia genuína que, longe de consistir num começo, se traduziria antes na compreensão de que toda a filosofia é um pensar do ser, um pensar

14 Martin Heidegger, Ontologie (Hermeneutik der Faktizität), GA63, p. 31. 
que, pertencendo ao ser, é iniciado por ele e apropriado pela facticidade de um acontecer que o apropria. Por outras palavras: o projeto heideggeriano de uma construção fenomenológica na e através da destruição da tradição ontológica converte-se paulatinamente na consciência de que não é a compreensão que inaugura o início fáctico de um acontecer, mas o próprio acontecer fáctico que, enquanto acontecimento que a apropria, determina sempre inicialmente esta mesma compreensão. É a partir desta tomada de consciência que Heidegger se começa a afastar do primeiro projeto mobilizador da sua filosofia, começando a falar num "outro início" da filosofia que, no fundo, ao invés de constituir o seu começo genuíno e definitivo, significaria antes o seu fim e a sua ultrapassagem: um "outro início" assente não numa supremacia do pensar, mas precisamente no seu retraimento e na sua assunção como pertença do próprio ser.

\section{$-3-$}

A partir destas observações, poderemos então, finalmente, considerar brevemente o terceiro e último ponto que nos propusemos abordar. Se o projeto heideggeriano de elaboração de uma ontologia fundamental se centrava numa análise preparatória do Dasein dirigida para uma construção fenomenológica e para uma "destruição" da tradição ontológica ocidental, de que modo esta mesma análise preparatória vai conduzir Heidegger para o "pensar da apropriação", para o Ereignis-denken, inviabilizando o projeto daquilo a que se poderia chamar a construção destrutiva que a ontologia fundamental constitui? A resposta à pergunta assim colocada não pode deixar de considerar brevemente a característica fundamental da análise preparatória do Dasein. Como se sabe, esta característica pode ser assinalada como a remissão para aquilo a que se poderia chamar o caráter não substancial desse mesmo Dasein. Ao invés do que se passa com o ente que participa do modo de ser da substância, o Dasein não encontra a sua essência numa presencialidade que determina previamente a sua existência fáctica, mas passa-se com ele precisamente o contrário: o modo de ser do Dasein é determinado por ser algo, à partida, já sempre seu (por uma Jemeinigkeit ${ }^{15}$ ), e a sua essência não pode deixar de ser entendida, de um modo verbal, como aquilo a que se poderia chamar um "estar a ser" a partir de uma facticidade que já sempre, nessa medida, constitui essa mesma essência. Por

15 Martin Heidegger, Sein und Zeit, Tübingen, Max Niemeyer, 1986, p. 42. 
outras palavras: como diz explicitamente Heidegger, o Dasein é o ente cuja existência, ou seja, cujo "estar-a-ser" ou essência entendida num sentido verbal, determina aquilo que ele é e precede, nessa medida, a essência entendida no sentido tradicional de uma quiditas. ${ }^{16}$ É então na medida em que a essência do Dasein não está aquém do "estar-a-ser" fáctico do Dasein, mas é antes precisamente determinada pela facticidade deste "estar-a-ser", que a ontologia fundamental não pode deixar de ser preparada, no entender de Heidegger, por uma "hermenêutica da facticidade".

Esta "hermenêutica da facticidade" parte do modo como o Dasein facticamente é a sua essência constituída por um estar-lançado (por uma Geworfenheit) no mundo. Como se sabe, em Ser e Tempo, Heidegger analisa a existência fáctica decorrente do estar-lançado do Dasein no mundo como uma dispersão nesse mesmo mundo, como um movimento de queda em relação a si e de fuga para o mundo, como um movimento que determina no Dasein que ele, à partida e quase sempre (zunächst und zumeist), não seja ele mesmo mas já sempre, de algum modo, algo não próprio, algo, neste sentido, inautêntico (uneigentlich). A inautenticidade do Dasein decorre então diretamente da queda própria do estar-lançado que determina essencialmente este mesmo Dasein na sua facticidade. E tal quer dizer que esta inautenticidade, de acordo com os inevitáveis resultados a que uma "hermenêutica da facticidade" propedêutica da ontologia fundamental conduziria, não poderia deixar de constituir o "como" da própria facticidade, marcando já sempre todas as suas possibilidades e esgotando, nessa medida, todos os seus modos de ser. É a partir desta conclusão inevitável que Heidegger escreve, em Ser e Tempo, que «a existência autêntica não é nada que paire sobre a cotidianidade cadente, mas existencialmente apenas um captar modificado desta». ${ }^{17} \mathrm{E}$ é também a partir dela que se pode compreender, por exemplo, que Heidegger caracterize a angústia, enquanto sentimento fundamental que confronta o Dasein consigo mesmo, como algo que acontece no Dasein do homem "só por instantes» ${ }^{18}$, ou que, nas lições de 1929-1930 sobre os Conceitos Fundamentais da Metafísica, Heidegger escreva sobre a essência do Dasein, marcada já sempre pelo seu "estar-a-ser" fáctico, que com o seu "estar-al" coincide já sempre um "estar-fora": "À essência do Dasein [estar-ai] pertence, enfim, o seu Weg-sein [estar-fora]. Este não é um evento qualquer, que às vezes entra em cena, mas um caráter essencial do próprio ser do homem:

\section{Idem.}

17 Martin Heidegger, Sein und Zeit, p. 179.

18 Martin Heidegger, "Was ist Metaphysik?”, Wegmarken, GA9, p. 111 
um como de acordo com o qual ele é; e isto de tal forma que um homem, porque existe, já sempre e necessariamente no seu Dasein [estar-ai], de algum modo, está fora». ${ }^{19}$

Confrontada com o projeto inicial da constituição de uma filosofia científica de base fenomenológica, de que deveria ser a análise preparatória, a hermenêutica heideggeriana da facticidade não poderia, então, deixar de adquirir uma função diferente daquela que tinha sido inicialmente prevista. Se um tal projeto tinha nascido a partir do plano fenomenológico de fundar o começo de uma filosofia científica, dir-se-ia, juntando-se à ideia da destruição e à parte não escrita de Ser e Tempo, que são os resultados da hermenêutica da facticidade que, antes de mais, confrontam Heidegger com o caráter insatisfatório de um tal plano, mostrando que a compreensão do Dasein nunca pode constituir-se como um começo fundador, escapando ao estar-lançado e à queda que já sempre o determina, e que a história da ontologia, enquanto história do pensar do ser, longe de poder ser compreendida como o fruto de um pensamento ainda não suficientemente fundado, é antes o acontecer de uma destinação do próprio ser, o acontecer de um ser que, ao endereçar-se no e através do pensar, simultaneamente se lhe subtrai e se furta ao seu domínio. A história do ser, a história do acontecer do ser no pensar, confirma-se aqui como a história de uma essencial "alienação" do ser, ou seja, a história de uma sua subtração essencial, cuja compreensão, segundo Heidegger, não pode deixar de exigir o sacrifício do projeto fenomenológico originário da fundação de uma filosofia científica. É por isso que, por exemplo, refletindo na Carta sobre o "Humanismo" em torno do abandono do projeto da ontologia fundamental, e proclamando a fecundidade do conceito de "alienação" em Marx para pensar a história como o acontecer de uma subtracção, Heidegger escreve que a fenomenologia de Sartre e de Husserl, por não reconhecer «o caráter essencial da historicidade no ser», não poderia ter um «diálogo produtivo com o marxismo». ${ }^{20} \mathrm{~A}$ partir deste reconhecimento, o início que pode ser esperado na filosofia passaria a ser não um começo fundador, mas um "apelo" que, perpassando ao longo da história do pensar, confrontaria este mesmo pensar com a sua finitude e pertença ao ser. E o percurso de pensamento de Heidegger é o percurso da paulatina confrontação com este início. Como resultado deste percurso, Heidegger marcará a diferença

19 Martin Heidegger, Die Grundbegriffe der Metaphysik: Welt - Endlichkeit - Einsamkeit, GA29/30, p. 95 (cita-se, ligeiramente modificada, a tradução de Marco Antônio Casanova: Os Conceitos Fundamentais da Metafisica: Mundo - Finitude - Solidão, Rio de Janeiro, Forense, 2003, p. 76).

20 Martin Heidegger, "Brief über den »Humanismus«, Wegmarken, GA9, p. 340. 
fundamental do início (Anfang) em relação a um mero começo (Beginn) ${ }^{21}$. E é a partir desta diferença que se pode ler o que Heidegger escreverá, por exemplo, no seu discurso de assunção do reitorado: «O início ainda é. Ele não se encontra atrás de nós como algo que foi há muito, mas está diante de nós. $\mathrm{O}$ início passa antecipadamente, enquanto aquilo que é maior, sobre tudo o que vem e, deste modo, também já sobre nós. O início invadiu o nosso futuro; ele encontra-se lá sobre nós, como a ordem longínqua para recuperar novamente a sua grandeza». ${ }^{22}$

Na década de 1930, Heidegger chamará ao pensar que se desenvolve a partir do abandono do projeto fenomenológico da ontologia fundamental um pensar do retraimento (Verhaltenheit). A escolha desta palavra alude, para Heidegger, à coincidência de um duplo movimento de subtracção ou de retirada: trata-se de um retraimento do pensar no acontecer do ser, ou seja, de um pensar que se abandona na pertença ao ser; mas trata-se também, ao mesmo tempo, de um retraimento do ser enquanto acontecer do ser na própria história do pensar. As Contribuições para a Filosofia, escritas por Heidegger entre 1936 e 1938, substituindo o caráter preparatório da hermenêutica da facticidade, são a propedêutica deste mesmo pensar: um pensar que, abandonando, por um lado, a pretensão da constituição do começo de uma filosofia científica suficientemente fundada e reconhecendo, por outro lado, que «o tempo dos sistemas passou $»^{23}$, encontra no "outro início" o espaço para um projeto filosófico sempre precário, que Heidegger identifica precisamente pela precariedade da falta de uma linguagem suficiente. Trata-se, nesta precariedade, de um projeto marcado por uma dupla negação: nem um início radical na história nem a abertura da verdade da história, mas a confrontação com o modo como na história a verdade sempre se lhe furta e subtrai.

21 Cf., por exemplo, as primeiras lições dedicadas a Hölderlin, no Semestre de Inverno de 1934-35: Martin Heidegger, Hölderlins Hymnen »Germanien« und »Der Rhein«, GA39, pp. 3-4: «O começo é aquilo com o que algo arranca; o início aquilo a partir do qual algo brota. [...] O começo é logo deixado para trás; desaparece no curso do acontecer. $\mathrm{O}$ início, a origem, pelo contrário, só no acontecer aparece e só está completo no seu fim. Quem muita coisa começa quase nunca chega ao início. E nós, homens, nunca podemos iniciar com o início - só um Deus o pode -, mas temos de começar, isto é, de arrancar com algo que conduz para a origem e a indica.»

22 Martin Heidegger, "Die Selbstbehauptung der deutschen Universität", Reden und andere Zeugnisse eines Lebensweges, GA16, p. 110. Usamos a nossa tradução publicada online: http://www. lusosofia.net/textos/heidegger_martin_auto_afirmacao_universidade_alema.pdf

23 Cf. nota 12. 
HEGEL, G.W.F. Hegel: Prefácios. Trad. de Manuel J. Carmo Ferreira, Lisboa, Imprensa Nacional - Casa da Moeda, 1990.

HEIDEGGER, Martin. GA9. Brief über den »Humanismus«. Org.F-W. Von Hermann, Frankfurt junto ao Main, 1976.

- GA24. Die Grundprobleme der Phänomenologie. Org.F-W. Von Hermann, Frankfurt junto ao Main, 1975.

. GA26. Metaphysische Anfangsgründe der Logik im Ausgang von Leibniz. Org.F-W. Von Hermann, Frankfurt junto ao Main, 1990.

- GA65. Beiträge zur Philosophie (Vom Ereignis). Org.F-W. Von Hermann, Frankfurt junto ao Main, 2003.

. GA63. Ontologie (Hermeneutik der Faktizität). Org.F-W. Von Hermann, Frankfurt junto ao Main, 1995.

- Sein und Zeit. Tübingen. Max

Niemeyer Verlag, 1986.

. GA9. Wegmarken. Was ist Metaphysik?. Org.F-W. Von Hermann, Frankfurt junto ao Main, 1976.

- GA9/30. Die Grundbegriffe der Metaphysik: Welt - Endlichkeit - Einsamkeit. Org.F-W. Von Hermann, Frankfurt junto ao Main, 2004.

Copilação bibliográfica feita pelos editores, a partir das referências indicadas em notas no corpo do texto - Os Conceitos Fundamentais da Metafísica: Mundo - Finitude - Solidão. Trad. de Marco Antônio Casanova, Rio de Janeiro, Forense Universitária, 2003.

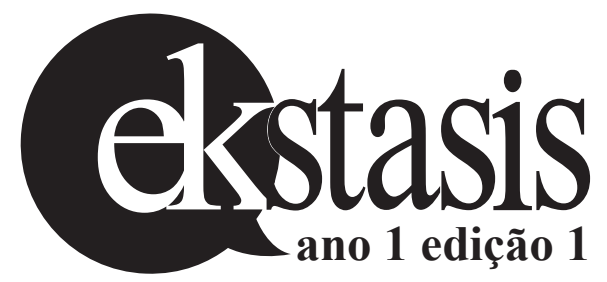

